\title{
Children's food supplements and compliance with health claim rules
}

\author{
A. W. Wicklow ${ }^{1}$, E. M. Keaveney ${ }^{1}$, M. C. Conway $^{1}$, S. M. Ní Bhriain ${ }^{1,2}$, F. E. Douglas ${ }^{1}$, \\ A. T. Carr $^{1}$ and M. A. T. Flynn ${ }^{1,2}$ \\ ${ }^{1}$ Public Health Nutrition, Food Safety Authority of Ireland, Dublin 1, Republic of Ireland and ${ }^{2}$ Northern Ireland Centre \\ for Food and Health, University of Ulster, Coleraine BT52 1SA, UK
}

\section{A.W. Wicklow awarded the 2014 FSAI student prize for oral communication}

Health claims permitted on food supplements exclusively targeting children are limited to child-specific health claims authorised under EU rules ${ }^{(1)}$. Food supplements placed on the Irish market are required to be notified to the Food Safety Authority of Ireland ${ }^{(2)}$. In this study the labels of food supplements exclusively targeting children notified during two time periods were examined for compliance with rules on health claims.

Food supplements notified between $1^{\text {st }}$ June 2010 and $31^{\text {st }}$ May 2011 (time period A, $n 1996$ ) and $1^{\text {st }}$ June 2012 and $31^{\text {st }}$ May 2013 (time period B, n1493) were assessed to identify those that exclusively targeted children. Major breaches were defined as use of 1 ) health claims not authorised for children, and 2) non-authorised health claims. Minor breaches were defined as authorised childspecific claims which 1) exaggerated the health benefit, 2) related the health benefit to the product per se and not the specific nutrient for which the claim was authorised, and 3) referred to a nutrient not present in the required amount.

Of the 1996 products notified in time period A, 456 included children in the target group. Of these, 56 were identified as targeting children exclusively, and the majority $(73 \% n 41)$ bore claims $(n 278)$. Of the 1493 products notified in time period B, 343 included children in the target group. Of these 103 were identified as targeting children exclusively and the majority (55\% $n 57)$ bore claims (n259). In both time periods most products bore more than one claim. The proportions (\%) of products in time period A and time period B that exclusively targeted children, and the health claims appearing on these that were compliant with, or in breach of, health claim rules, were compared - see table.

\begin{tabular}{|c|c|c|c|c|}
\hline & \multicolumn{2}{|l|}{ Time period $\mathrm{A}$} & \multicolumn{2}{|l|}{ Time period $\mathrm{B}$} \\
\hline & Products (n56) & Claims $(n 278)$ & Products $(n 103)$ & Claims $(n 259)$ \\
\hline No claims $\%$ (n) & $27(15)^{*}$ & $0(0)$ & $45(46)^{*}$ & $0(0)$ \\
\hline Compliant claims\% (n) & $0(0)$ & $5(13)^{* *}$ & $7(7)$ & $18(46)^{* *}$ \\
\hline Minor claim breaches $\%(\mathrm{n})$ & $5(3)$ & $4(11)$ & $6(6)$ & $7(17)$ \\
\hline Major claim breaches $\%(n)$ & $68(38)^{*}$ & $91(254)^{* *}$ & $43(44) *$ & $76(196)^{* *}$ \\
\hline
\end{tabular}

$* p<0.05,{ }^{* *} p<0.001$.

There were significantly less products exclusively for children in time A compared to B $(12 \% v s .30 \%, p<0.001)$. There were significantly more claims on the products exclusively for children, in time period A, compared to time period B $(73 \% v s .55 \%, p<0.05)$. As shown in the table, significantly more products in time A bore claims with major breaches of health claim rules, compared to those in time period B. In addition, there were significantly less compliant claims in time period A compared to time period B. In both time periods, the most common major breaches were use of general non-specific health claims that were not accompanied by the necessary authorised child-specific health claim, and use of claims authorised for adults. The minor breaches that were most common in both time periods concerned exaggeration of the health benefits.

The majority of notified food supplements exclusively for children bear health claims which are in breach of rules. However, there was an improvement in food supplements complying with rules on health claims in the most recent time period compared with the earlier period.

1. Regulation (EC) $1924 / 2006$ on nutrition and health claims made on food.

2. S.I. No. 506 of 2007 European communities (food supplements) regulations 2007 (as amended). 